\title{
Homenagem ao Prof. Luiz CARlos Nogueira
}

\author{
Maria Lúcia de Araújo Andrade ${ }^{1}$ \\ Instituto de Psicologia - USP
}

$\mathrm{E}_{\mathrm{s}}^{\mathrm{s}}$ stes últimos dias, desde aquele em que faleceu, repentinamente, o Professor Luiz Carlos Nogueira, têm sido de muito luto, tristeza e dor na Universidade de São Paulo e em especial no Instituto de Psicologia. Todos nós, amigos, colegas, funcionários e parentes choramos sua perda. Dói-me muito falar no passado pois isso presentifica e denuncia inexoravelmente a perda enorme que tivemos. Não era minha intenção ler aquilo que apenas escrevi com a intenção de me nortear em momento tão difícil, pois tanto o conheci, mas se eu tiver de fazê-lo quando a voz se embargar, me perdoem pois a emoção e o luto estão presentes em mim.

Conheci Luiz Carlos Nogueira há muitos anos, no fim da década de 60, quando ainda aluna do então Curso de Psicologia, comecei a notá-lo. Soube que tinha consultório com Durval Marcondes e que trabalhava no Serviço de Higiene Mental do Estado, importante lugar onde este havia implantado um atendimento institucional psicológico-psicanalítico inovador.

Soube, também, que ele havia sido seminarista e iniciado um curso em 1955, em Filosofia, na Faculdade de Filosofia Nossa Senhora Medianeira, em Friburgo, quando pensara em fazer uma carreira religiosa na ordem dos Jesuítas. Obtivera seu diploma em 1960 e, à mesma época, abandonou essa pretensão para dar assistência à sua mãe que enviuvara e à irmã que necessitaria de sua proteção.

Em 1961, entrou para o Curso de Especialização em Psicologia Clínica da Faculdade de Filosofia, Ciências e Letras da USP, histórica origem do

1 Chefe do Departamento de Psicologia Clínica do Instituto de Psicologia - USP 
Departamento de Psicologia Clínica, sob a responsabilidade da Professora Anita Marcondes Cabral e dirigido pelo Professor Durval Marcondes, o introdutor da Psicanálise em São Paulo e no Brasil .

Quanto à sua Formação, inicioura na Psicanálise tradicional, nos mo ldes da Sociedade Brasileira de Psicanálise de São Paulo, continuando-a depois junto àqueles que trouxeram as idéias de Lacan ao Brasil .

Luiz Carlos Nogueira foi um inovador que pôde muito bem se situar nos moldes da nossa Universidade, sempre em transformações constantes, onde, em 1972, o Curso de Psicologia se tornou o atual Instituto de Psicologia com os seus Departamentos.

Convidado que foi para dar aulas no Departamento de Psicologia Crnica, apresentou sua Dissertação de Mestrado e, pouco tempo depois, sua Tese de Doutorado, onde comenta a obra de Paul Ricoeur, importante autor e filósofo francês que, na década de 60, manteve uma constante e profícua interlocução com Lacan. Sua Livre Docência, realizada na década de 90, foi o seu último passo na carreira universitária e é uma síntese de todos os pontos importantes que defendeu durante sua carreira de Professor.

É voz corrente ter sido ele um dos expoentes do Departamento de Psicologia Clínica do IP- USP, e o foi, não somente pela inovação no ensino da Psicanálise, que introduziu em 1976, quando no nível da pós-graduação, iniciou o ensino da teoria desenvolvida, na França, por J. Lacan, mas também pela dedicação e empenho que nessa atividade sempre teve em relação ao preparo de seus alunos para o exercício da clínica.

A essa mesma época, fundou com outros colegas, o Centro de Estudos Freudianos (CEF), empreendimento que consumiu, por largo tempo, muito de sua energia e que foi o primeiro grupo brasileiro de estudos de Lacan.

Participei, como membro fundador, dessa reunião inaugural, no Prédio Ilhas do Sul, em um conjunto residencial próximo à Universidade, como ele jocosamente fazia questão de se referir, e de muitas outras onde o vi junto com a psicanalista Joana Helena Cunha Ferraz, sua primeira esposa. Ela o auxiliou muito nesse pimeiro período, com alegria, valentia e afinco, na criação e solidificação dessa importante instituição nacional, que congregou 
Homenagem ao Prof. Dr. Luiz Carlos Nogueira por Ocasião da sua Missa...

diversos Centros de Estudos e onde era possível se estudar e pesquisar a teoria freudiana e lacaniana, nas mais diversas regiões do Brasil. Garantolhes que se me sobrar tempo, engenho e arte ainda escreverei a história desse primeiro movimento lacaniano, em São Paulo.

Porém, não foi só na Psicanálise que Luiz Carlos se fez notar pelas suas atividades. Foi de suma importância, para sua carreira e para a Universidade, seu trabalho relacionado ao Curso de Ética que sempre ministrou em nossa Graduação. Sua participação mais recente, mas não menos intensa, consistiu na formação e estabelecimento da Comissão de Ética, que presidiu até a sua morte, dentro do Instituto de Psicologia.

Sempre atento em colaborar com a administração do Departamento, nunca se recusou, nesses 30 anos, a participar das muitas comissões onde sua presença foi solicitada, nem nas diversas atividades administrativas que incluíram desde o exercício da Chefia do Departamento até a sua constante presença no Conselho Departamental. Sua atuação, em tais situações, sempre representou um fator de crescimento e conciliação pela firmeza elegante e cuidadosa com que defendia suas posições bastante avançadas e coerentes.

Dizia-se já da dedicação, atenção e cuidados que ele tinha em seus atendimentos como Clínico e não só quando se tratava do seu consultório particular. Isso eu soube e testemunhei bem de perto, através de uma daquelas fontes que muitas vezes temos, que não tem porque nos enganar e que nos contam, quase que por acaso, um fato.

Uma amiga próxima de minha família, que tinha um neto com problemas psicológicos sérios, levou-o ao Serviço de Higiene Mental onde foi atendida juntamente com a criança, pelo psicanalista Luiz Carlos Nogueira. Falou-me muito comovida da sua gentileza, seriedade, competência e dedicação já que esse tratamento se estendeu por um largo prazo.

Pouco tempo depois, conheci-o melhor nesse aspecto profissional. O de Clínico, que a meu ver vai além daquele do excelente professor, que sempre foi, já que o escolhi para cuidar de um dos meus enteados, pois nessa época eu me casara novamente. 
Sabemos, por outro lado, não ser a situação profissional, a única para se saber quem é uma pessoa. Assim, tendo sido sua aluna, tendo um parente próximo como seu cliente e, pouco depois, já formada em Psicologia, sua colega de Departamento e de consultório, na Oliveira Dias 341, pude conviver com ele nas mais diversas situações e conhecê-lo melhor.

O convívio no Consultório, onde trabalhamos juntos mais de dez anos com outros colegas psicanalistas, foi uma oportunidade muito interessante e rara de sabê-lo na sua vida pessoal, onde era sempre encantador. Sua mãe, Amélia Lousão Nogueira, senhora altiva e muito exigente para com ele, lá aparecia para falar com o filho e ele pacientemente a recebia. Sua frágil irmã, Clara Augusta Nogueira, apelido Clarinha, ia buscar no irmão um olhar de afeto e uma palavra boa e sempre os conseguia. Seus filhos muitas vezes ali se faziam notar, por uma razão ou outra, pois afinal não só o pai, mas a mãe também trabalhavam lá e, assim, os conheci um a um.

Paulo, o mais velho, já então parecido com o pai; Sílvia, a pequena guerreira, que ainda hoje é; a loirinha, Márcia, a médica. Só bem mais tarde surgiu a muito festejada, Lúcia, a artista. ${ }^{2}$

Algumas dessas expressões ele as usava nos tempos atuais quando eu lhe perguntava de seus filhos e de seus três netos, que seriam quatro daqui a algum tempo e que foram chegando devagarzinho.

Luiz Carlos se comovia bastante quando eu lhe indagava dos filhos, fossem esses que mencionei, ou aquele, Marcelo ${ }^{3}$, filho do primeiro casamento de Helena Bicalho e que lhe veio trazido prontinho, como dádiva, anos depois.

Havia um paradoxo nesse homem, que sendo arrojado era também tímido, sendo tão capaz mostrava-se, às vezes, com alguns pequenos desajei-

2 Paulo Ferraz Nogueira é casado com Silvana Arjona Ferraz Nogueira, e seus filhos são Gu ilherme e Gabriela; Silvia Ferraz Nogueira De Tommaso é casada com Mario De Tommaso Jr., cujo filho é Lucas; Márcia Ferraz Nogueira Isaias é casada com Flávio Isaias, cuja filha é Bruna; Lucia Ferraz Nogueira de Souza Dantas é casada com Luiz Rodolfo Arariboia de Souza Dantas.

3 Marcelo Bicalho Behar, filho do primeiro casamento de Helena M. Bicalho. 
Homenagem ao Prof. Dr. Luiz Carlos Nogueira por Ocasião da sua Missa...

tos e dificuldades em se organizar na vida diária. Porém, tinha a qualidade de saber pedir ajuda e despertar o carinho, os cuidados e a colaboração de todos nós que o rodeávamos, colegas, funcionários, amigos e familiares. Era sempre, nesses como em outros momentos, muito cordial e gentil. Sempre se poderia ouvir dele um "Muito Obrigado".

Anos mais tarde, já estando vivendo então com Helena M. Bicalho, fundou A Escrita Freudiana, grupo que se sobrepôs ao extinto CEF. Se Luiz Carlos Nogueira era um homem de idéias da hora, bem sabia que sozinho não as levaria avante e procurou sempre se rodear daqueles que poderiam colaborar com ele, acrescentando alguma coisa aos empreendimentos que realizou e estava realizando até a véspera de sua morte.

Helena foi para Luiz Carlos a grande companheira dos últimos tempos. Auxiliouro deveras, com grande entusiasmo participativo, dando-lhe uma retaguarda impecável em todos os seus últimos projetos. Desejamos que possa se recuperar dessa dor infinita para continuar o seu próprio trabalho e o dele.

Luiz Carlos Nogueira - professor, supervisor, psicanalista, o homem de família, amigo- foi uma figura notável. Sempre amável, gentil, cordial e elegante em seus gestos e maneiras, o que era a sua maior marca... Sempre cuidadoso com o próximo, amigo e colega leal em todas as circunstâncias, nunca deixou de emitir, corajosa e francamente as suas opiniões. Assim se manifestou e se portou em toda a sua vida e nos mais diversos momentos dela.

Há muito a ser contado sobre ele, há muito a ser dito mas não será agora, nesse momento de pesar em que todos estamos aqui orando juntos por ele.

Porém, prometemos, nós aqui, representando o Instituto de Psicologia, que faremos tudo para que sua memória permaneça entre nós na forma em que ela mais se fixa: pela palavra escrita e publicada.

Dessa forma pensamos retribuir seu trabalho realizado a mais das vezes pela trans missão oral, nas aulas, na formação de seus alunos, na dedicação enquanto clínico, fatos esses que não the possibilitaram ter deixado obra escrita maior, pois a morte o levou muito cedo, ainda no apogeu de sua vida! 